\title{
MEDO E APOIO AO AUTORITARISMO NA CONTEMPORANEIDADE
}

Fear and support for authoritarianism in contemporary times

Ana Carolina Morais Colombarol Mestre em Direito pela Universidade Estadual Paulista Júlio de Mesquita Filho. Docente na Libertas Faculdades Integradas, Universidade Estadual Paulista Júlio de Mesquita Filho, São Paulo, Brasil carolcolombaroli@hotmail.com [D https://orcid.org/0000-0002-1825-0097

A lista completa com informações dos autores está no final do artigo

\section{RESUMO}

O presente trabalho busca empreender uma reflexão acerca do medo, enquanto afeto político central, que constrói os laços sociais, tanto do ponto de vista das relações interpessoais quanto do ponto de vista mais amplo das relações políticas, discutindo as facetas da insegurança na contemporaneidade, a apropriação do discurso e das práticas de medo e insegurança pelo Estado neoliberal e pelo Capital, e a relação estabelecida entre o medo e a adesão a posições e proposições políticas conservadoras e autoritárias. Para tanto, parte-se de uma perspectiva da Teoria Crítica, considerando a maneira como a vida social e a experiência política mobilizam os afetos, com atenção especial voltada ao medo na contemporaneidade, conjugada com a utilização de pesquisas empíricas já realizadas que corroboram, direta ou indiretamente, a relação entre o medo e o apoio ao autoritarismo.

Palavras-chave: Medo. Teoria Crítica. Afeto Político. Autoritarismo.

\begin{abstract}
This paper aims to undertake a reflection on fear as a central political affection. This affection builds social bonds, as from interpersonal relations, as well from the broader point of view of political relations. It also discusses the facets of insecurity in contemporary times, the appropriation of the discourse and the practices of fear and insecurity by the neoliberal state and the Capital. Furthermore, it shed light on the relationship between fear and adherence to conservative and authoritarian political positions and propositions. In order to do so, it uses Critical theory for considering the way social life and political experience mobilize affections, with particular attention on contemporary fear. Empirical research evidence corroborates, directly or indirectly, the relationship between fear and support for authoritarianism.
\end{abstract}

Keywords: Fear. Critical theory. Political affect. Authoritarianism.

\section{SOBRE UMA ADESÃO SOCIAL DOS AFETOS}

Vladimir Safatle, na introdução de seu O Círculo dos Afetos, incita a teoria crítica a partir de uma nova forma de entender a sociedade

[...] é possível que uma perspectiva crítica precise atualmente partir de uma compreensão distinta do que é a sociedade. Talvez precisemos partir de uma constatação de que sociedades são, em seu nível mais fundamental, circuitos de afetos. Enquanto sistemas de reprodução material de formas hegemônicas de vida, sociedades dotam tais formas de força de adesão ao produzir continuamente afetos que nos fazem assumir certas possibilidades de vida a despeito de outras. Devemos ter sempre em mente que formas de vida determinadas se fundamentam em afetos específicos, ou seja, elas precisam de tais afetos para continuar a se repetir, a impor seus modos de 
ordenamento definido, com isso, o campo dos possíveis. Há uma adesão social construída através das afecções (SAFATLE, 2016, p. 15-16).

A construção da adesão social por meio dos afetos nos ajuda a compreender as razões para que formas de vida específica permanecem, mesmo quando em desatendimento aos critérios normativos que elas mesmas fundamentavam. Não é a adesão tácita a um conjunto normativo que produz a coesão social, mas sim circuitos de afetos que desempenham esse papel de modo concreto (SAFATLE, 2016, p. 16). A partir de uma perspectiva freudiana, é a partir da mobilização dos afetos que os indivíduos produzem crenças, desejos e interesses, justificando, para si mesmos, a necessidade de aderir à uma determinada norma, obedecendo um rol de comportamentos prescritos e rejeitando outros (SAFATLE, 2016, p. 38).

A vida psíquica, tal como entendida, com seus conflitos, sofrimentos e desejos, é uma produção de modos de circuito de afetos e, a própria noção de afeto está inserta em uma dinâmica de imbricação que descreve a alteração produzida por algo que aparentemente se origina do exterior e que nem sempre se constitui com objeto da consciência representacional. Assim, desde o princípio, o social está presente no Eu. "Ser afetado é instaurar a vida psíquica através da forma mais elementar de sociabilidade, essa sociabilidade que passa pela aiethesis ${ }^{1}$ e que, em sua dimensão mais importante, constrói vínculos inconscientes" (SAFATLE, 2016, p. 38). Pode-se considerar, portanto, que a política e a forma de se fazer política, é um modo de produção do circuito dos afetos.

Theodor Adorno (1972; 1975; 1991), tendo em vista a compreensão da adesão dos movimentos e massa ao fascismo, bem como da personalidade autoritária, já apontava a necessidade de completar a teoria da sociedade com a psicologia.

Desde hace más de treinta años se perfila entre las masas de los países altamente industrializados la tendencia a abandonarse en manos de una política de la catástrofe en lugar de perseguir intereses racionales, y ante todo, la conservación de su propia vida. Se les prometen ciertas ventajas, es verdad, pero a la vez se sustituye con ahínco el ideal de su propia felicidad por la violencia y la amenaza, se las carga con sacrificios desmesurados, se pone en peligro inmediato su existencia y se apela a latentes deseos de muerte. Algo de ello es tan abiertamente visible para los sujetos concernidos que, a quien se esfuerce por comprender, se le hace difícil conformarse con lo verdaderamente decisivo, con mostrar las condiciones objetivas de los movimientos de masas, y no sucumbir a la sugestión de que ya no rige ninguna ley objetiva. La antigua explicación de que los interesados en tal situación controlan todos los medios de opinión

${ }^{1}$ A palavra grega "aisthesis" pode ser entendida como "faculdade de sentir" ou "compreensão pelos sentidos". Tem a mesma origem da palavra aistheticon, que significa "o que sensibiliza", aquilo que afeta os sentidos. Podemos compreender a palavra, no contexto, como uma afetação/interação entre o sujeito e o que está no mundo exterior. 
pública ya no basta por sí sola. Pues las masas apenas se dejarían atrapar por una propaganda burda y falsa hasta frotarse los ojos si algo en ellas mismas no diera acogida a mensajes que hablan de sacrificarse y de vivir peligrosamente. Por eso, teniendo a la vista el fenómeno fascista, se juzgó necesario completar la Teoría de la sociedad con la Psicología, sobre todo una Psicología social orientada psicoanalíticamente (ADORNO, 1991, p. 135).

A necessidade de integrar à teoria social elementos da psicologia, como levantado por Adorno para a compreensão do nazifascismo, faz-se também necessário para compreender este início de século XXI. Tanto nas Américas como na Europa, é visível o crescimento da adesão a posições e proposições políticas conservadoras e/ou autoritárias, muitas vezes acompanhadas pelo desprezo (e, até mesmo ódio ${ }^{2}$ ) à democracia e aos direitos humanos. Para compreender os impasses e vínculos sociopolíticos que ora se põem, é fundamental refletir sobre os afetos "no sentido de uma consideração sistemática sobre a maneira como a vida social e a experiência política produzem e mobilizam afetos que funcionarão como base de sustentação geral para a adesão social” (SAFATLE, 2016, p. 37).

No contexto econômico neoliberal, não seria exagerado falar em um período de "fim das certezas", em que, não só a nível nacional, mas mundial, é mais possível projetar horizontes utópicos de esperança/expectativa. Há de se lidar com a dimensão contingente dos acontecimentos. Ante transformações profundas e cada vez mais rápidas, preocupase com o pungente e urgente. Presente e futuro são marcados pela constante incerteza, pelo desamparo e pelo medo.

É precisamente o terceiro afeto acima mencionado, o objeto de estudo do presente ensaio: o medo, enquanto afeto político central, que constrói os laços sociais, tanto do ponto de vista das relações interpessoais quanto do ponto de vista mais amplo das relações políticas, e a forma como este medo repercute na violência e no apoio a posturas e posições políticas autoritárias.

\section{A GESTÃo POLÍTICA E ECONÔMICA PELO MEDO}

Não é nova a ideia de que o medo é um afeto político central. Thomas Hobbes, em Leviatã, escrito em 1651, já analisava como o medo opera enquanto ferramenta da ordem

${ }^{2}$ Cf. RANCIĖRE, Jacques. O ódio à democracia. Trad. Mariana Echalar. São Paulo: Boitempo, 2014. 
política, ao passo que leva o indivíduo a submeter-se à norma, possibilitando a vida em sociedade.

Segundo Hobbes, ante a inobediência a um poder central, os homens viviam em estado de natureza, em uma guerra de todos contra todos

[...] durante o tempo em que os homens vivem sem um poder comum capaz de mantê-los todos em temor respeitoso, eles se encontram naquela condição a que se chama guerra; e uma guerra que é de todos os homens contra todos os homens. Pois a guerra não consiste apenas na batalha ou no ato de lutar, mas naquele lapso de tempo durante o qual a vontade de travar batalha é suficientemente conhecida. [...] a natureza da guerra não consiste na luta real, mas na conhecida disposição para tal, durante todo o tempo em que não há garantia do contrário. [...] Portanto, tudo aquilo que se infere de um tempo de guerra, em que todo homem é inimigo de todo homem, infere-se também do tempo durante o qual os homens vivem sem outra segurança senão a que lhes pode ser oferecida pela sua própria força e pela sua própria invenção. Numa tal condição não há lugar para o trabalho, pois o seu fruto é incerto; consequentemente, não há cultivo da terra, nem navegação, nem uso das mercadorias que podem ser importadas pelo mar; não há construções confortáveis, nem instrumentos para mover e remover as coisas que precisam de grande força; não há conhecimento da face da Terra, nem cômputo do tempo, nem artes, nem letras; não há sociedade; e o que é pior do que tudo, um medo contínuo e perigo de morte violenta. (grifo nosso) (HOBBES, 2003, p. 109).

Para o filósofo contratualista, a obediência às normas e ao poder central, a necessidade de um governo, a estabilização da sociedade, ao estabelecimento de obrigações, lugares, previsões de comportamento, a conservação das relações de autoridade, seriam decorrentes do medo:

As paixões que fazem os homens tender para a paz são o medo da morte, o desejo daquelas coisas que são necessárias para uma vida confortável e a esperança de as conseguir por meio do trabalho. $E$ a razão sugere adequadas normas de paz, em torno das quais os homens podem chegar a um acordo (HOBBES, 2003, p. 111).

De todas as paixões, a que menos faz os homens tender a violar as leis é o medo. Mais: excetuando algumas naturezas generosas, é a única coisa que leva os homens a respeitá-las (HOBBES, 2003, p. 253).

Existiria, assim, uma cumplicidade entre razão e medo, não somente por ser a razão impotente sem o medo, mas porque o medo seria, em Hobbes, uma espécie de "paixão universal calculadora", permitindo o cálculo das consequências possíveis a partir da memória dos danos, fundamento para a deliberação racional e a previsibilidade da ação (BODEI apud SAFATLE, 2016, p. 43).

O Estado hobbesiano seria, portanto, um Estado de proteção social, que se serve de todo poder possível, instaurando um domínio de legalidade próprio, sem preocupar-se com valores ou verdade, sem limites, para assegurar a existência física daqueles que domina e 
protege. Este Estado, tal qual previsto por Hobbes, legitima sua soberania pela capacidade de amparo e segurança de seus cidadãos, perpetuando continuamente a imagem de violência desagregadora que está sempre à espreita, ou da morte violenta sempre iminente, caso o espaço social deixe de ser por ele controlado. "Um Estado construído a partir da dessocialização de todo vínculo comunitário, constituindo-se como espaço de uma 'relação de não relações'” (SAFATLE, 2016, p. 45).

Este Estado, que depende do medo para sua legitimação enquanto todo-poderoso protetor, produz mais violência e explora os efeitos psicológicos do medo de tal violência, perpetuando a dependência de seus cidadãos em relação a si. É necessário, para sua sobrevivência enquanto força de amparo, a provocação contínua do sentimento de desamparo, da iminência de estado de guerra, da iminência da completa vulnerabilidade.

\subsection{Você tem medo de que?}

A sociedade neoliberal contemporânea em muito não se difere da sociedade de insegurança total apresentada por Hobbes em Leviatã. No entanto, a insegurança contemporânea não advém somente da falta de proteção, mas principalmente da fragilidade e complexidade que trazem em si mesmos os sistemas de segurança, que podem falhar em suas tarefas e decepcionar as expectativas que suscitaram. Robert Castel (2005, p. 9) parte da hipótese de que

[...] as sociedades modernas são construídas sobre o terreno da insegurança, porque são sociedades de indivíduos que não encontram, nem em si mesmos, nem em seu entorno imediato, a capacidade de assegurar sua proteção. Se é verdade que essas sociedades estão ligadas à promoção do indivíduo, elas também promovem sua vulnerabilidade, ao mesmo tempo em que o valorizam. Daí resulta que a busca de proteção é consubstancial para o desenvolvimento destes tipos de sociedades. Mas esta busca se assemelha em certos aspectos aos esforços empregados para encher um tonal das Danaides que deixa sempre escoar o perigo. O sentimento de insegurança não é exatamente proporcional aos perigos reais que ameaçam a população, é antes o efeito de um desnível entre uma expectativa socialmente construída de proteção e as capacidades efetivas de uma determinada sociedade de coloca-las em prática.

A fragilidade dos sistemas de segurança nos foi demonstrada com a redução significativa das proteções sociais no último quarto do século $X X$. Com o enfraquecimento do Estado-nacional, a supremacia do mercado, a decadência da sociedade salarial, o desemprego em massa, a precarização das relações de trabalho, a individualização das tarefas e das trajetórias profissionais, o indivíduo deixou de estar protegido contra os riscos sociais "clássicos" (acidente, doença, desemprego, incapacidade de trabalhar...), sofrendo 
as mudanças socioeconômicas, colocado em situação de vulnerabilidade, e individualmente responsabilizado, tendo que enfrentar as situações, assumir as mudanças e encarregar-se de si mesmo.

De outro lado, a sociedade é posta diante de uma nova geração de riscos industriais, tecnológicos, sanitários, naturais, ecológicos, etc. -, consequência da promoção da modernidade, da tentativa de controle da natureza, do desenvolvimento das ciências e tecnologias que se voltam contra o meio ambiente.

A insegurança vem de todos os lados, está em todos os lugares. Há insegurança e medo em relação aos desastres naturais, decorrentes das mudanças climáticas e ambientais ora experimentadas, quando proliferam-se terremotos, inundações, furacões, deslizamentos, secas e ondas de calor; há insegurança e medo nas relações com outras pessoas, que podem, em nosso imaginário, devastar os lares e empregos, destruir os corpos mediante ataques terroristas, crimes violentos, agressões sexuais; experimenta-se ainda a insegurança e o medo em relação a fenômenos que não são nem humanos nem naturais, e ambos ao mesmo tempo, o medo de que os barris de petróleo sequem, de que a bolsa de valores entre em colapso, de que grandes companhias desapareçam - e, juntamente com elas, milhares de empregos -, de que sejam desvalorizados os ativos mais preciosos, e quaisquer outras catástrofes que estão prontas para esmagar a tudo e a todos. A cada dia, novos perigos são descobertos e anunciados, e não se pode saber quantos e quais ainda podem surgir (BAUMAN, 2008, p. 11-12).

O discurso e as práticas de medo e insegurança são apropriados pelo Estado, pela Mídia e pelo Capital. O ajustamento social é fundamentado em um grande poder coercitivo: "a ameaça social internalizada, o medo, converte-se em um poderoso motivador psíquico para o ajustamento do modus operandi do administrado" (SILVA, 2015, p. 39)

No mundo do trabalho, o estado permanente de insegurança é apropriado pelo Capital, para garantir a submissão dos trabalhadores e explorar ainda mais a sua maisvalia. Para Adorno, comportar-se em desacordo com as regras econômicas apavora o indivíduo, por deixa-lo a margem da sociedade em que se insere:

[...] quien no se comporta según las reglas económicas raramente se arruina al momento. Pero en el horizonte apunta el desclasamiento. Se vuelve visible el camino que lleva a lo asocial, a lo criminal: rehusarse a participar en el juego hace sospechoso, y expone a la venganza social incluso a quien no necesita pasar hambre ni dormir bajo los puentes. Pero la angustia a ser expulsado, la sanción social del comportamiento económico, se ha interiorizado hace mucho junto con otros tabúes, y ha cuajado en el individuo. Se ha convertido históricamente en su segunda naturaleza; no es gratuito que existencia «Existenz», en el uso lingüístico no corrompido 
filosóficamente, signifique por igual la existencia natural como la posibilidad de autoconservación en el proceso económico. El Superyó, la instancia de la conciencia moral "Gewissen», no sólo le pone al individuo ante los ojos la prohibición como lo malo en sí mismo, sino que además amalgama de forma irracional la antigua angustia ante la aniquilación física con la angustia, mucho más tardía, de dejar de formar parte de la asociación social que rodea a los seres humanos en lugar de la naturaleza (ADORNO, 1991, p. 139).

Silvia Viana, em sua tese Rituais de Sofrimento, em que compara o mercado de trabalho contemporâneo com os reality shows, explica de que forma se dá a apropriação do sentimento de insegurança pelo Capital, no mundo do trabalho:

[...] há um gap entre o mais-trabalho de quem se entende virtualmente demitido, e o sacrifício violento de si e dos outros em nome da permanência, e não se trata de uma diferença de grau. O discurso de instabilidade no mundo do trabalho gera mais trabalho e submissão, mas pode abrir as portas para um contra-argumento bastante razoável: se não há e nem pode haver garantias, para que tamanho comprometimento? Por isso, é fundamental a compreensão da "exclusão" para além de sua dimensão discursiva. Mais que uma representação invertida da realidade, a aniquilação econômica e social é uma Lei, infundada e incompreendida. Mais - ou menos, já que se trata de uma ideologia elementar - que uma explicação, a "exclusão" é um axioma. Seu suplemento narrativo já apresenta a inconsistência imanente a esse termo base da LTI contemporânea: a sua "fatalidade meteorológica". Por isso a oscilação conjuntural dos índices de emprego e desemprego não é capaz de alterar um sentimento de mundo fundado na insegurança, assim como os índices da segurança pública em nada alteram o medo permanente do Bandido. [...] Todos sabem que o mundo não acaba para além do "paredão", que aquilo não é, de fato, a condenação à morte que atuam. O mesmo ocorre com relação à "exclusão", ainda que saibamos que, infelizmente, não há um "lado de fora" do sistema produtivo capitalista, agimos como se habitássemos à beira do abismo. A "exclusão" e o "paredão" não funcionam porque convencem, mas porque a eliminação tornou-se um ritual ao qual o trabalho se vê constantemente submetido (RODRIGUES, 2011, p. 50).

O modelo neoliberal, com toda sorte de desenvolvimento tecnológico, ao invés de promover uma libertação do homem em relação ao trabalho, resulta num mundo em que nunca se trabalhou tanto e nunca o trabalho foi tão importante como eixo de virtude social. O trabalho contemporâneo mobiliza todas as esferas da vida do trabalhador e ocupa todos os momentos de sua vida, num paradoxo em que não é mais o emprego o centro de preocupação das pessoas, e sim o desemprego.

A conquista da mobilização total ocorre menos por sedução que por ameaça. Concomitante ao desenvolvimento do galanteio gerencialista e da sub-cultura de auto-ajuda nasceu o fim dos tempos neoliberal e sua cultura de guerra. A adesão entusiástica das inteligências é mediada pelo medo. "O medo como motor da inteligência!". Foi o que descobriu Dejours em suas pesquisas a respeito do sofrimento no trabalho: "Até alguns anos atrás, pensávamos que a mobilização subjetiva da inteligência e da 
engenhosidade no trabalho repousava na livre vontade dos trabalhadores. (...) Só em nossas pesquisas mais recentes foi que pudemos constatar um outro possível motor da inteligência no trabalho. Sob a influência do medo, por exemplo, como a ameaça de demissão pairando sobre todos os agentes de um serviço, a maioria dos que trabalham se mostra capaz de acionar todo um cabedal de inventividade para melhorar sua produção" (RODRIGUES, 2011, p. 109).

O desemprego estrutural, já previsto por Marx, decorrente do desenvolvimento de tecnologias de automação e declínio da necessidade de trabalho humano, acentua o medo de exclusão social, e mostra-se essencial ao capitalismo neoliberal para que ele possa extrair cada vez mais trabalho, empenho e inventividade de seus trabalhadores, fazendo crescer seus lucros.

Soma-se ao medo da exclusão social o medo da morte violenta, mais primitivo e mais coercitivo. E tal afeto é largamente mobilizado pela política e pelo Estado burguês, que num ciclo, a fim de garantir sua permanência, para oferecer proteção, depende da constante insegurança. Segundo Paulo Arantes (2007, p. 306),

[...] a segurança tornou-se a principal mercadoria da indústria política do medo. O mesmo para a antimercadoria da insegurança sistêmica: tanto o Estado quanto sua ampliação midiática precisam dela, o primeiro para vender proteção, a segunda para alimentar campanhas de alarme social e clamor punitivo.

Pesquisas empíricas demonstram o tamanho do medo da violência. Segundo pesquisa de opinião sobre segurança pública realizada pela Fundação Perseu Abramo (BOKANY, 2015), a violência ${ }^{3}$ e a segurança ${ }^{4}$ situam-se, respectivamente, em segundo e terceiro lugar no ranking dos principais problemas do Brasil, ficando atrás somente da saúde, e na frente da educação, corrupção e administração pública, problemas sociais, desemprego, problemas econômicos e outros. Somando-se as preocupações com a violência e com a segurança, estas ultrapassam as preocupações com saúde. Dentre todos os entrevistados, $82 \%$ afirma que a delinquência/criminalidade aumentou muito nos últimos dois anos; $75 \%$ crê que nos últimos dois anos a delinquência/criminalidade em sua cidade aumentou; para $69 \%$ a situação de segurança pública no Brasil está pior; $54 \%$ afirma que a sua sensação se segurança pessoal e da sua família está pior; $49 \%$ crê que o serviço prestado pela polícia em seu bairro está pior.

\footnotetext{
${ }^{3}$ A pesquisa considera como "violência" o assalto, roubo e furto, as drogas e a violência em geral.

${ }^{4} \mathrm{O}$ termo "segurança", na pesquisa, engloba falta de policiamento/rondas, falta de policiais e
} segurança em geral. 
De fato, a situação da segurança pública no Brasil é calamitosa ${ }^{5}$. Mas, de outro lado, a literatura aponta para o fato de que as pessoas tendem sempre a associar o medo sentido por elas à violência ou ao aumento desta. Pesquisas realizadas na França, Austrália, Inglaterra, Suécia (países com índice de criminalidade bem mais baixos que o Brasil), África do Sul e América do Sul mostram que as pessoas, ao serem indagadas sobre o seu principal temor, colocam a violência em primeiro lugar. No entanto, os pesquisadores afirmam que a violência criminal não é a causa principal do medo, apontando para outros elementos que contribuem para o aumento do medo e da insegurança (AGUIAR, 2005, p. 110).

Mas o Estado, com o apoio da mídia, alimenta esse discurso de medo, porque precisa dele. Empreendo "guerra às drogas", "guerra ao crime organizado", intervenções militares, gestiona o sentimento constante de insegurança, ao mesmo tempo em que o intensifica, justificando seus arbítrios e ilegalismos, sob a justificativa de manter seguros e protegidos os seus cidadãos.

Em artigo publicado em 2003 na Folha de São Paulo, Jacques Rancière explica a necessidade da guerra para a perpetuação do Estado neoliberal. A guerra é necessária não para dar resposta a uma situação de insegurança, real ou imaginária, mas justamente para manter esse sentimento de insegurança, imprescindível para o bom funcionamento dos Estados.

O Estado neoliberal é diferente da propaganda capitalista, que o descreve como aquele que tem seu poder diluído e invisível, harmônico e em sincronia com os fluxos de mercadoria e informação, um Estado do consenso automático, de ajustamento sem dor entre negociação coletiva do poder e negociação individual dos prazeres no interior da sociedade democrática de massas, despassionalizando os conflitos. Em oposição ao propagandeado, o Estado neoliberal adquire uma nova face, com armas, hinos a Deus e à bandeira, retorno à propaganda de Estado, um revival nacionalista. Na América pósreaganiana e na Inglaterra pós-tatcheriana, bem como no restante do mundo capitalista neoliberal, o consenso não é aquele do Estado gestor, mas sim baseado no medo de uma sociedade que se aglomera em torno de um Estado policial, que se sustenta e se aproveita

${ }^{5}$ A taxa de homicídios no Brasil é de quase 30 a cada 100 mil habitantes, impressionantemente alta, se comparada com a média mundial, de 6,9 homicídios a cada 100 mil habitantes. 
de um sentimento, com a ajuda da propaganda realizada pelos meios de comunicação de massa, da comunidade do medo (RANCIÈRE, 2003).

Se o autor escreve seu texto em relação aos Estados Unidos da América e países europeus, à época em guerra no Iraque, a análise pode muito bem ser aplicada ao caso brasileiro e a atual "guerra às drogas e ao crime organizado".

Paulo Arantes (2007, p. 310), analisando o texto de Rancière e indo além, escreve que as grandes cidades (quer de metrópoles, quer das colônias), curvam-se aterrorizadas e aterrorizáveis ao vazio político, em que sequer é possível imaginar um futuro alternativo ao presente que se coloca à frente. As sociedades contemporâneas são "comunidades de medo", agrupadas sobre a "proteção" ambígua e duvidosa de um Estado que subsiste pela gestão exclusiva de um sentimento coletivo de insegurança. São cada vez menos "sociedades nacionais". Dá-se uma integração perversa pelo medo, e seu avesso de ilegalismos e conflitos sempre à beira da explosão violenta.

Safatle (2015), em entrevista afirma que a política se transformou em gestão social do medo, analisando o campo político e a maneira como são conduzidos e mobilizados os discursos a respeito da imigração, do terrorismo, de uma "perda do nosso espaço natural", do Estado-nação.

\section{MEDO E AUTORITARISMO}

O medo primitivo da morte violenta, tal qual descrito por Hobbes, leva os homens a seguir as regras, e também os leva a perseguir um Estado nos moldes hobbesianos: forte, protetor, todo-poderoso para garantir a sobrevivência numa era de incertezas e, como não poderia deixar de ser com estas características, autoritário.

Com transformações sociais ocorrendo em alta velocidade, uma das consequências vivenciadas é a falta de estruturação do campo cognitivo do indivíduo, gerando grande ansiedade e insegurança. O indivíduo busca, no autoritarismo e no preconceito, soluções para essa insegurança e ansiedade. Adorno e seus colaboradores escrevem, nessa linha, em A Personalidade Autoritária, demonstrando que o autoritarismo é uma tendência geral a colocar-se em situações de dominância ou submissão, como consequência de uma insegurança básica do Eu (BERNAL, 1981, p. 41).

Do ponto de vista social, o autoritarismo encontra seu principal terreno de cultivo em situações derivadas da ausência de normas sociais, da crise econômica, política e cultural, e na ameaça e no medo geral de que as próprias condições de vida se tornem piores. 
Nas sociedades contemporâneas, verifica-se uma crise que envolve o modelo global do mundo capitalista ocidental, com o aumento dos ganhos das classes altas, sem correspondente aumento da ocupação laboral e consequente redistribuição da riqueza produzida. A geração crescida no final do século $X X$ foi a primeira dos tempos modernos que não melhorou de condições sociais, econômicas e culturais em relação a seus pais. A crise geral do Estado de Bem-Estar social contribui para pior as condições de vida de todas as pessoas que dele dependem para sua própria subsistência e sobrevivência e, pela primeira vez, afeta algumas classes sociais que até agora não haviam sido afetadas pelos ciclos de crise econômica: a classe média vê piorar sua situação de forma repentina e drástica. Ademais, na Europa, chegam ondas imigratórias provenientes de países de "terceiro mundo". Além da classe média, que uma vez já declarou seu apoio ao fascismo e ao nazismo, o proletariado urbano, que teme a piora das suas condições de vida, também está exposto à influência da nova direita (ROCCATO; CONVERSO, 1996, p. 65).

Medo e regressão andam lado a lado, em esferas da cultura que se acreditava há muito desencantadas. O fanatismo religioso e movimentos de massas ressurgem com força, e a irracionalidade visível de seus membros se transforma em suportes subjetivos para o exercício do poder político e econômico (SILVA, 2015, p. 44).

Adorno (1972, p. 417-418), em seu Teoria Freudiana e o Padrão da Propaganda Fascista, afirma que a propaganda fascista é psicológica por causa de fins autoritários e irracionais, que não podem ser alcançados por meio de convicções racionais, mas sim pelo habilidoso despertar de uma "porção da herança arcaica do sujeito". O seguidor fascista apresenta um comportamento político inconciliável com seus próprios interesses racionais como pessoa privada, bem como com os do grupo ou classe social a que pertence de fato. É despertada uma irracionalidade que, do ponto de vista do líder, tem que ser uma convicção baseada não em percepções e raciocínios, mas em um vínculo erótico.

Já nos estudos sobre A Personalidade Autoritária (1975), Adorno e seus colaboradores buscavam estudar o sujeito potencialmente fascista, cuja estrutura de personalidade o faz especialmente suscetível à propaganda antidemocrática, a partir da hipótese fundamental de que a suscetibilidade de um indivíduo ser absorvido pelo autoritarismo depende, principalmente, de suas necessidades psíquicas. Segundo Crochik (2008, p. 303) o estudo

[...] traz como hipótese central a existência de uma mentalidade que contemplaria simultaneamente a posição política individual e preconceitos contra minorias; tal mentalidade seria mediada por necessidades profundas 
da personalidade que, por sua vez, se desenvolvem por meio de instituições sociais.

A mais célebre construção de Adorno em A Personalidade Autoritária (1975), foi a Escala de Fascismo ( $F)$, cujo fator de autoritarismo por ela medido compõe-se, de nove sub-variáveis teóricas: 1) Convencionalismo: adesão rígida aos valores da classe média; 2) Submissão autoritária: atitude de submissão e aceitação incondicional acerca das autoridades morais idealizadas do endogrupo; 3) Agressividade autoritária: tendência a buscar e condenar, rechaçar e castigar os indivíduos que violam os valores convencionais; 4) Anti-intracepção: oposição ao subjetivo, a autorreflexão e à introspecção; 5) Superstição e estereotipia: crença na determinação sobrenatural do destino humano e inclinação a pensar a partir de categorias rígidas; 6) Poder e força: preocupação com a dimensão dominação-submissão, forte-fraco, líder-seguidor em suas relações interpessoais, identificando-se com as figuras que representam o poder e valorizando em excesso a forma e a dureza; 7) Destrutividade e cinismo: hostilidade generalizada, vilipêndio do humano; 8) Projetividade: ao projetar para o exterior os impulsos emocionais inconscientes, as pessoas autoritárias tendem a crer que no mundo acontecem coisas desenfreadas e perigosas e; 9) Sexo: preocupação exagerada com as questões sexuais. Tais variáveis foram pensadas para que, juntas, formassem uma única síndrome, uma estrutura mais ou menos duradoura no indivíduo que o torna receptivo à propaganda antidemocrática.

Fato é que, contemporaneamente, as tendências - bem como as propagandas autoritárias crescem no mundo ocidental. Donald Trump foi eleito nos EUA com o slogan Make America Great Again, propalando pautas reacionárias em relação a direitos civis e humanos, e à democracia no restante do mundo. Na Europa, uma das opções políticas que mais canalizam o descontentamento, particularmente da classe trabalhadora, é o da ultradireita, sendo claro o caso francês, com a Frente Nacional, dirigida por Le Pen. O Brasil elegeu Jair Bolsonaro no ano de 2018, um candidato que durante a campanha presidencial fez intensa defesa do regime militar, de torturadores, promoveu preconceitos contra homossexuais, negros, mulheres e outras minorias.

Segundo The Economist Intelligence Unit, em seu Democracy Index 2017, que avalia o pluralismo eleitoral, participação e cultura política, liberdades civis e funcionamento do governo, o índice atribuído ao Brasil caiu de 7,38 para 6,9 entre 2006 e 2016. O Informe Latinobarômetro 2017 apresenta dados que corroboram o crescimento do autoritarismo no país: segundo a pesquisa realizada, apenas $32 \%$ dos brasileiros consideravam, no ano de 2016, que a democracia era preferível a qualquer outra forma de governo, com um recuo 
de 22 pontos percentuais em relação ao 2015 (quando eram 54\%) e diante de uma média latino-americana de 54\%. Em pesquisa realizada pelo Pew Research Center, foi verificado que $67 \%$ dos brasileiros estão insatisfeitos com o funcionamento do regime democrático, 27\% apoiariam um "líder forte sem interferência parlamentar", 38\% apoiariam um governo militar, e que $23 \%$ são atraídos por opções não democráticas, enquanto apenas $21 \%$ estão comprometidos com a democracia.

Dirigentes políticos e autoridades têm investido no discurso autoritário, explorando politicamente o medo da população e fazendo crescer as tendências autoritárias. O Fórum Brasileiro de Segurança Pública (LIMA et. al, 2018), considerando este quadro, elaborou uma pesquisa sobre o Índice de Propensão ao apoio a Posições Autoritárias, procurando demonstrar os rumos das disputas por narrativas políticas e como elas são controladas pelo medo da violência presente na população adulta brasileira. A pesquisa, baseando-se na escala psicométrica formulada por Adorno (Escala F) e suas posteriores releituras, aplicou questionário com 17 assertivas a 2.087 pessoas, em uma amostra estatisticamente representativa da população brasileira com 16 anos ou mais e em 130 municípios de pequeno, médio e grande porte.

A pesquisa encontrou um Escore Médio de 8,10 de apoio a posições autoritárias, indicando forte propensão de adesão a questões contidas nas subdimensões analisadas e ao autoritarismo de forma geral ${ }^{6}$. Segundo os autores, analisando o escore

E, se calcularmos os escores separadamente para cada subdimensão, é possível notar [...] que a subdimensão que mais se destaca no Brasil é aquela associada à submissão à autoridade, que explicaria vários aspectos

\footnotetext{
${ }^{6} \mathrm{Na}$ dimensão Submissão à Autoridade, responderam afirmativamente $83 \%$ dos entrevistados que "não há nada pior do que uma pessoa que não sente profundo amor, gratidão e respeito pelos seus pais"; $81 \%$ que "a obediência e respeito a autoridade são as principais virtudes que devemos ensinar às nossas crianças"; $69 \%$ que "o que este país necessita, principalmente, antes de leis ou planos políticos, é de alguns líderes valentes, incansáveis e dedicados, em quem o povo possa depositar a sua fé"; $68 \%$ que "nenhuma pessoa decente, normal ou em seu juízo pensaria em ofender um amigo ou parente próximo"; $53 \%$ que "o policial é um guerreiro de Deus para impor a ordem e proteger as pessoas de bem". Na dimensão Agressividade Autoritária, responderam afirmativamente $79 \%$ que "hoje em dia, as pessoas se intrometem cada vez mais em assuntos que deveriam ser pessoais e privados"; $77 \%$ que "se falássemos menos e trabalhássemos mais, todos estaríamos melhor"; $69 \%$ que "os crimes sexuais tais como o estupro ou ataques a crianças merecem mais que prisão; quem comete esses crimes deveria receber punição física publicamente ou receber um castigo pior"; $68 \%$ que "às vezes, os jovens têm ideias rebeldes que, com os anos, deverão superar para acalmar os seus pensamentos"; $60 \%$ que "a maioria de nossos problemas sociais estaria resolvida se pudéssemos nos livrar das pessoas imorais, dos marginais e dos pervertidos"; $45 \%$ que "devese castigar sempre todo insulto à nossa honra" e 13\% que "os homossexuais são quase criminosos e deveriam receber um castigo severo". Na dimensão Convencionalismo, responderam afirmativamente $75 \%$ que "a ciência tem o seu lugar, mas há muitas coisas importantes que a mente humana jamais poderá compreender"; $64 \%$ que "todos devemos ter fé absoluta em um poder sobrenatural, cujas decisões devemos acatar"; $54 \%$ que "um indivíduo de más maneiras, maus costumes e má educação dificilmente pode fazer amizade com pessoas decentes"; $44 \%$ que "os homens podem ser divididos em duas classes definidas: os fracos e os fortes" e $31 \%$ que "pobreza é consequência da falta de vontade de querer trabalhar" (LIMA et. al., 2018, p. 13).
} 
da nossa cultura política e do atual cenário político e das perspectivas eleitorais para 2018, inclusive as recentes pesquisas eleitorais. $E$ não somente vinculado a questões eleitorais, a população brasileira necessita de figuras de liderança que podem ser representadas pelo fortalecimento de grupos radicais e de celebridades virtuais presentes em diversas plataformas e redes sociais (grifo nosso) (LIMA et. al, 2018, p. 14).

A referida pesquisa buscou avaliar, para além da propensão ao apoio a posições autoritárias, de que forma a violência - seja emanada das relações sociais cotidianas, do crime organizado ou como padrão de ação do Estado - associa-se a uma série de déficits democráticos para compor o cenário de medo e insegurança que interfere na política e nas instituições. Para associar o medo da violência e mensurar seu impacto na propensão ao apoio de posições autoritárias, inseriu uma bateria de quesitos na mesma pesquisa que o índice, objetivando conhecer o grau de medo da população em relação a um conjunto de situações, elaborando um índice sintético de medo da violência, posteriormente cruzado com a Escala (LIMA et. al., 2018, p. 21). Encontrou-se um índice médio de medo de 0,68, um patamar moderado de medo da violência. Dividiram, então, a amostra por quartis, sendo o primeiro quartil composto pelos $25 \%$ dos indivíduos com menos medo e, o quarto quartil composto pelos $25 \%$ com mais medo da amostra (LIMA et. al., 2018, p. 21).

Quando cruzados os índices de medo da violência com os de propensão ao apoio das posições autoritárias, verificou-se que o grupo com mais medo tende a aderir com mais intensidade ao autoritarismo: "mais medo provoca mais adesão a soluções autoritárias, sendo essa diferença significativa em comparação com os com menos medo" (LIMA et. al., 2018, p. 22).

Com base nas medidas de medo e de autoritarismo, verifica-se que o medo da violência é fator importante, influenciando o rumo do debate político e das posições adotadas pela população, sendo incorporado, mobilizado e priorizado pelos atores políticos, fazendo avanças discursos autoritários e antidemocráticos.

Os resultados do índice de autoritarismo sugerem que segmentos que enxergam na aniquilação autoritária da cidadania e da liberdade a forma de impor e manter a ordem, a moral e os bons costumes parecem ganhar eco a partir das incertezas sociais e políticas (LIMA et. al., 2018, p. 23).

A correlação entre o medo e o autoritarismo vai ao encontro de outras pesquisas realizadas sobre a demanda punitiva, violações de direitos humanos e posições autoritárias dela decorrentes. Em pesquisa realizada pelo mesmo Fórum Brasileiro de Segurança Pública, foi identificado que $50 \%$ dos residentes nas grandes cidades brasileiras concordam com a frase "Bandido bom é bandido morto", sendo esse percentual maior entre os 
moradores da região Sul do país (54\%), entre os autodeclarados brancos $(53,5 \%)$ e entre os homens (52\%) (FÓRUM, 2015, p. 7). A já citada pesquisa realizada pela Fundação Perseu Abramo diagnosticou uma demanda punitiva na maior parte da população: 84,8\% dos entrevistados acreditam que a quantidade de notícias sobre a violência estão de acordo com a criminalidade; $89 \%$ crê que os menores de idade que cometem crimes violentos devem ser julgados como adultos; 90,5\% afirma que a idade penal deve diminuir, e dentre estes, $42 \%$ afirma que deve diminuir para 13 ou 15 anos; $85 \%$ afirma que penas mais rigorosas diminuem a criminalidade e 54\% acredita que a ação violenta dos criminosos justifica a violência policial.

\section{CONCLUSÃO}

Os Estados neoliberais não são capazes de proteger suas populações contra as incertezas do mercado, os riscos ambientais, as mazelas da segurança pública e, nos países europeus e EUA, contra atentados terroristas longamente planejados. No entanto, e justamente por isso, se apropria e administra os sentimentos de medo e insegurança, pois a própria existência do Estado e seu poder, sua reprodução e renovação estão calcados no medo e na insegurança. Para assegurar a sua continuidade, legitimar-se como força de amparo o Estado necessita do constante sentimento de desamparo, do medo da extrema vulnerabilidade (SAFATLE, 2016, p. 45).

A compreensão da emergência de figuras autoritárias neste início do século XXI devem ter em conta que as dinâmicas que conduzem ao autoritarismo não são um fenômeno exterior, mas uma latência interna às sociedades democráticas (SAFATLE, 2016, p. 73), considerando-se que as convicções políticas, sociais e econômicas dos indivíduos constituem uma pauta que expressa tendências profundas da personalidade (ADORNO, 1975, p. 146). A adesão social pelos afetos é própria não só das sociedades totalitárias, mas está fortemente presente nas democracias liberais e na própria noção de Estado. Nas democracias liberais também há espaço para a adesão a uma lógica autoritária e para a transformação da política em gestão da fobia (SAFATLE, 2016, p. 76).

$\mathrm{E}$, diante de um quadro de cada vez mais medo e insegurança, visíveis e invisíveis, reais e irreais, as massas aderem a uma irracionalidade, agindo de modo contrário aos seus próprios interesses ou do grupo de que fazem parte, sucumbindo e, ao mesmo tempo, 
sustentando uma política engendrada pelo princípio da dominação, permeada por interesses de manutenção de uma ordem social injusta.

As sociedades modernas estão abertas ao retorno de figuras superegoicas de autoridade (SAFATLE, 2016, p. 73) pois as massas, diante de um quadro de insegurança, ao lado da frustração ante a um Estado que não atende às demandas sociais, passam a buscar um líder - uma figura paterna onipotente e não controlada, retornado à ideia do todo-poderoso e ameaçador pai primitivo - em uma figura política (ADORNO, 1972, p. 416).

O medo contemporâneo, que guarda uma grande semelhança com o medo hobbesiano, quando explorado pelo Capital e pela política neoliberal, é capaz de produzir, no seio das democracias liberais, um Estado autoritário, sem preocupações de cunho democrático ou social.

\section{REFERÊNCIAS}

ADORNO, Theodor W. De la relación entre sociología y psicología. In: ADORNO, Theodor W Actualidad de la filosofía. Barcelona, Paidós, 1991, pp. 135-204.

ADORNO, Theodor W. Freudian theory and the pattern of fascist propaganda. In:

ADORNO, Theodor W Gesammelte Schriften, 8.II. Frankfurt: Suhrkamp Verlag, 1972. p. 408-433

ADORNO, Theodor W. Studies in the Authoritarian Personality. In: ADORNO, Theodor W. Gesammelte Schriften, 9 .II. Frankfurt: Suhrkamp Verlag, 1975. p. 144-508.

AGUIAR, Cristiane Lamin Souza. Medo e descrença nas instituições de lei e ordem: uma análise da imprensa escrita e das sondagens de opinião. (Dissertação Mestrado em Sociologia) Faculdade de Filosofia, Letras e Ciências Humanas. Universidade de São Paulo. 2005.

ARANTES, Paulo E. Extinção. São Paulo: Boitempo, 2007.

BAUMAN, Zygmunt. Medo líquido. Tradução de Carlos Alberto Medeiros. Rio de Janeiro: Zahar, 2008.

BERNAL, Anastasio Ovejero. El autoritarismo: enfoque psicológico. El Basilisco: Revista de materialismo filosófico, n. 13, p. 40-44, 1981.

BOKANY, Vilma (coord.). Pesquisa de opinião pública: segurança pública. Janeiro de 2015. São Paulo: Fundação Perseu Abramo; Fundação Rosa Luxemburgo, 2015.

Disponível em: http://novo.fpabramo.org.br/media/18748

CASTEL, Robert. A insegurança social: o que é ser protegido? Tradução de Lucia M. Endlich Orth. Petrópolis, RJ: Vozes, 2005. 
CORPORACIÓN Latinobarómetro. Informe 2017. Buenos Aires: Latinobarômetro, 2017. Disponível em: http://www.latinobarometro.org/LATDocs/F00006433InfLatinobarometro2017.pdf Acesso em: 10 jul. 2018.

CROCHIK, José Leon. T.W. Adorno e a psicologia social. Psicologia \& Sociedade, Porto Alegre, v. 20, n. 2, p. 297-305, ago. 2008.

FÓRUM Brasileiro de Segurança Pública. Anuário Brasileiro de Segurança Pública 2015. São Paulo: Fórum Brasileiro de Segurança Pública, 2015. Disponível em: http://www.forumseguranca.org.br/produtos/anuario-brasileiro-de-seguranca-publica/9oanuario-brasileiro-de-seguranca-publica Acesso em: 1 out. 2015.

HOBBES, Thomas. Leviatã. Trad. João Paulo Monteiro, Maria Beatriz Nizza da Silva, Claudia Berliner. São Paulo: Martins Fontes, 2003.

LIMA, Renato Sérgio de et. al. Medo da violência e o apoio ao autoritarismo no Brasil: índice de propensão ao apoio a posições autoritárias. São Paulo: Fórum Brasileiro de Segurança Pública, 2017.

PEW Research Center: Globally, Broad Support for Representative and Direct Democracy. out. 2017. Disponível em: < http://www.pewglobal.org/2017/10/16/globallybroad-support-for-representative-and-direct-democracy Acesso em: 10 jul. 2018.

RANCIĖRE, Jacques. O princípio de insegurança. Folha de São Paulo, 21 de setembro de 2003, caderno Mais!, p. 3. Disponível em:

https://www1.folha.uol.com.br/fsp/mais/fs2109200303.htm Acesso em: 05 jul. 2018.

RODRIGUES, Silvia Viana. Rituais de sofrimento. São Paulo: [s.n], 2011. Tese (Doutorado em Sociologia). Universidade de São Paulo. Programa de Pós-Graduação do Departamento de Sociologia da Faculdade de Filosofia, Letras e Ciências Humanas.

ROCCATO, Michele; CONVERSO, Daniela. Cómo y porqué es necesario volver a estudiar el autoritarismo. Psicología Política, v. 13, p. 63-79, 1996.

SAFATLE, Vladimir. Entrevista: O medo se transformou em elemento da gestão social. Gaúcha ZH. Publicada em: 14 nov. 2015. Disponível em:

https://gauchazh.clicrbs.com.br/porto-alegre/noticia/2015/11/vladimir-safatle-o-medo-setransformou-em-elemento-da-gestao-social-4902621.html Acesso em: 05 jul. 2018.

SAFATLE, Vladimir. O círculo dos afetos: corpos políticos, desamparo e fim do indivíduo. 2. ed. Belo Horizonte: Autêntica Editora, 2016.

SILVA, Pedro Fernando. Psicologia Social de Adorno: resistência à violência do mundo administrado. Psicologia \& Sociedade, Belo Horizonte, v. 27, n. 1, p. 35-46, Abr. 2015. Disponível em: http://www.scielo.br/scielo.php?script=sci arttext\&pid=S010271822015000100035\&lng=en\&nrm=iso Acesso em: 06 jul. 2018.

THE ECONOMIST Intelligence Unit. Democracy Index 2017: Free speech under attack. Londres: The Economist, 2018. Disponível em: http://pages.eiu.com/rs/753-RIQ-

438/images/Democracy Index 2017.pdf Acesso em: 10 jul. 2018. 


\section{Notas}

Ana Carolina de Morais Colombaroli

Mestre em Direito pela Universidade Estadual Paulista Júlio de Mesquita Filho.

Doutoranda no Programa de Pós-Graduação Integração da América Latina pela Universidade de São Paulo.

Docente na Libertas Faculdades Integradas, Curso de Direito, São Sebastião do Paraíso, Brasil. Docente no Centro Universitário Estácio,

Curso de Direito, Ribeirão Preto, Brasil.

carolcolombaroli@hotmail.com

D. Dhttps://orcid.org/0000-0002-1825-0097

Endereço de correspondência do principal autor

Rua São Francisco de Assis, n 339, ap. 3, Jd. Castelo Branco, CEP 14.090-550, Ribeirão Preto/SP, Brasil.

\section{AGRADECIMENTOS}

Ao professor Gustavo José de Toledo Pedroso, pelas valiosas sugestões.

\section{CONTRIBUIÇÃO DE AUTORIA}

Concepção e elaboração do manuscrito: A. C. M. Colombaroli

Discussão dos resultados: A. C. M. Colombaroli

Revisão e aprovação: A. C. M. Colombaroli

Caso necessário veja outros papéis em: https://casrai.org/credit/

\section{CONJUNTO DE DADOS DE PESQUISA}

Todo o conjunto de dados que dá suporte aos resultados deste estudo foi publicado no próprio artigo.

\section{FINANCIAMENTO}

NÃO SE APLICA

\section{CONSENTIMENTO DE USO DE IMAGEM}

NÃO SE APLICA

\section{APROVAÇÃO DE COMITÊ DE ÉTICA EM PESQUISA NÃO SE APLICA}

\section{CONFLITO DE INTERESSES \\ NÃO SE APLICA}

\section{LICENÇA DE USO}

Os autores cedem à Revista Internacional Interdisciplinar INTERthesis os direitos exclusivos de primeira publicação, com o trabalho simultaneamente licenciado sob a Licença Creative Commons Attribution (CC BY) 4.0 International. Estra licença permite que terceiros remixem, adaptem e criem a partir do trabalho publicado, atribuindo o devido crédito de autoria e publicação inicial neste periódico. Os autores têm autorização para assumir contratos adicionais separadamente, para distribuição não exclusiva da versão do trabalho publicada neste periódico (ex.: publicar em repositório institucional, em site pessoal, publicar uma tradução, ou como capítulo de livro), com reconhecimento de autoria e publicação inicial neste periódico.

\section{PUBLISHER}

Universidade Federal de Santa Catarina. Programa de Pós-graduação Interdisciplinar em Ciências Humanas. Publicação no Portal de Periódicos UFSC. As ideias expressadas neste artigo são de responsabilidade de seus autores, não representando, necessariamente, a opinião dos editores ou da universidade.

\section{EDITORES}

Javier Ignacio Vernal e Silmara Cimbalista.

\section{HISTÓRICO}

Recebido em: 30.01.2019 - Aprovado em: 17.11.2019 Publicado em: 31.01.2020 